Revista de Derecho YACHAQ

ISSN: 1817-597x (impresa) / ISSN: 2707-1197 (en linea)

Centro de Investigación de los Estudiantes de Derecho (CIED)

Universidad Nacional de San Antonio Abad del Cusco

N. ${ }^{\circ} 10-2019$

[pp. 129-139]

Fecha de recepción: 12/08/19

Fecha de aceptación: 18/09/19

\title{
Sistema de tutela jurisdiccional civil colectivo
}

\section{Collective Civil Jurisdictional Guardianship System}

\author{
Victor Mamani Olivera[*]
}

\begin{abstract}
RESUMEN: teniendo en cuenta el modelo económico-comercial actual, que tiene entre algunas de sus características, ser global, transnacional y estar orientado a vincularse de forma directa o indirecta con grandes grupos o colectividades (masas) y generar consecuencias jurídicas de carácter colectivo, es fundamental que el Derecho Civil se oriente a brindar tutela material y jurisdiccional colectiva; Por tal motivo, corresponde revisar (conceptualmente) el Sistema de Tutela Jurisdiccional peruano, caracterizado por ser personalista que no resulta suficiente para atender situaciones jurídicas de carácter colectivo. Una alternativa importante viene a ser El Sistema de Tutela Jurisdiccional Civil Colectivo, que permite recurrir a instancia judicial ejercitando la acción colectiva, la representación adecuada, un proceso colectivo y un pronunciamiento que al adquirir la calidad de cosa juzgada tiene efectos expansivos -erga omnes-.
\end{abstract}

ABSTRACT: taking into account the current economic-commercial model, which has among some of its characteristics, being global, transnational and oriented towards linking directly or indirectly with large groups or collectivities (masses) and generating legal consequences of a collective nature, it is essential that the Civil Law is oriented to provide collective material and jurisdictional protection; For this reason, it is appropriate to review (conceptually) the Peruvian Jurisdictional Guardianship System, characterized by being a personalist that is not sufficient to address collective legal situations. An important alternative is the Collective Civil Jurisdictional Guardianship System, which allows recourse to judicial action exercising collective action, adequate representation, a collective process and a pronouncement that when acquiring the quality of res judicata has expansive effects -erga omnes-.

PALABRAS CLAVE: sistemas de tutela, tutela individual, tutela colectiva, derechos colectivos.

KEYS WORDS: guardianship systems, individual guardianship, collective guardianship, collective rights.

[*] Bachiller en Derecho por la Universidad Nacional de San Antonio Abad de Cusco.

Contacto: estudiard@gmail.com 


\section{PRELIMINARES}

\subsection{Sistema jurídico}

No cabe duda de que las sociedades se encuentran organizadas a nivel político, social, económico y jurídicamente; es muy probable que existan otros criterios de organización de las mismas atendiendo a diferentes factores como, por ejemplo, el religioso. Como se puede advertir, una de las formas de organización es la jurídica, la cual ha permitido la generación de diferentes sistemas jurídicos. Así, tenemos como sistemas jurídicos contemporáneos a: el Sistema Jurídico Romano Germánico, el Common Law, Sistema de Países Religioso, Sistema de Países Socialista (David y Jauffret, 2010).

Un significado de esta institución jurídica nos lo proporciona Huerta (2003), quien refiere:

El sistema jurídico es entendido como un conjunto de elementos y las relaciones entre sí, determinable como una unidad. Estos elementos son las normas jurídicas y sus contendidos, así como los procedimientos de creación que se encuentran previstos en las normas. (p.122)

Por su parte, el profesor Alexy (2004) considera que el sistema jurídico comprende tanto a un sistema de normas como a un sistema de procedimientos:

Como un sistema de procedimientos, el sistema jurídico es un sistema de acciones basadas en reglas y guiadas por reglas, a través de las cuales las normas son promulgadas, fundamentadas, interpretadas, aplicadas e impuestas. En tanto sistema de normas, el sistema jurídico es un sistema de resultados o productos de procedimientos de creación de normas, cuales quiera que sean sus características. Se pueden decir que quien considera que el sistema jurídico es un sistema de normas se refiere a su costado externo. En cambio, se trata del costado interno cuando el sistema jurídico es considerado como un sistema de procedimientos. (p. 31)

Es de advertir que la validez jurídica de las normas tiene como fundamento la Constitución
Política, la cual señala las condiciones que permiten determinar si una norma pertenece a un sistema jurídico.

Con lo expresado por Alexy, podemos señalar que un sistema jurídico se encuentra conformado por un sistema de normas (conjunto de normas o sistema material de derechos) y por un sistema de procedimientos (sistema de tutela jurisdiccional de derechos), los mismos que asociados están encaminados a la tutela y protección de derechos.

Según lo expresado por el profesor Guilhermen Marinonni, la tutela de derechos cuenta con dos modalidades, la primera, referida a la tutela de derechos prestada por normas de derecho material y, la segunda, referida a la tutela jurisdiccional mediante normas procesales, es decir, con la primera se reconocen derechos y con la segunda se garantiza que sean protegidos, así como su respeto forzoso.

\subsection{Sistema de Tutela Jurisdiccional}

De manera específica, el sistema de tutela jurisdiccional está referido al acceso a instancia judicial, y comprende a la acción como el ejercicio de un derecho y a la jurisdicción como la intervención del Estado a cargo de un tercero denominado juez.

En palabras del profesor Sumaria (2010), el sistema de tutela jurisdiccional:

Está compuesto en la interacción de la acción y la jurisdicción, a través del proceso. En este sistema, el «proceso» como mecanismo de interacción de la acción (sociedad) y la jurisdicción (Estado) presentan variantes de acuerdo a la opción política del Estado, ya sea en una democracia neoliberal o una democracia social, de acuerdo a los modelos políticos del siglo XXI. (p. 14)

Se puede advertir que los actores en la tutela jurisdiccional vienen a ser el Estado a través del juez y la sociedad a través de las partes.

Para mejor comprensión se elabora el presente cuadro: 
Cuadro N. ${ }^{\circ} 1$

\begin{tabular}{|c|c|c|c|}
\hline \multicolumn{4}{|c|}{ Sistema de Tutela Jurisdiccional } \\
\hline Acción & \multirow{3}{*}{ Proceso } & \multicolumn{2}{|c|}{ Jurisdicción } \\
\hline \multirow{2}{*}{ Sociedad } & & \multicolumn{2}{|l|}{ Estado } \\
\hline & & D. social & D. neoliberal \\
\hline Partes & Activista o de competencia & Juez & \\
\hline
\end{tabular}

Fuente: Mamani Olivera, 2019

La conceptualización realizada por el profesor Sumaria nos permite entender que la tutela jurisdiccional es un sistema, al ser «un conjunto de elementos en interacción y relación entre Estado y sociedad». Desde un enfoque económico, refiere que el sistema de tutela jurisdiccional con la eficiencia productiva de la economía. Así, afirma:

[...], los factores de producción de la justicia que son la acción y la jurisdicción, y que finalmente cuyo modelo productivo (modelo procesal) que se ha de adaptar debe estar de acuerdo con los objetivos del Estado. (Sumaria, 2010, p. 43)

El siguiente cuadro nos permite vincular la tutela jurisdiccional con la eficiencia productiva (criterio económico).

\section{Cuadro N. ${ }^{\circ} 2$}

\section{Sistema de Tutela Jurisdiccional y su correlación} con el criterio económico de eficiencia productiva

\begin{tabular}{|c|c|c|c|}
\hline \multirow{2}{*}{$\begin{array}{c}\text { Criterio } \\
\text { económico } \\
\text { de eficacia } \\
\text { productiva }\end{array}$} & \multicolumn{2}{|c|}{$\begin{array}{l}\text { Factores de } \\
\text { producción de justicia }\end{array}$} & $\begin{array}{c}\text { Modelo } \\
\text { productivo } \\
\text { (Modelo }\end{array}$ \\
\hline & Acción & Jurisdicción & $\begin{array}{l}\text { Objetivos del } \\
\text { Estado }\end{array}$ \\
\hline
\end{tabular}

Fuente: Mamani Olivera, 2019

Atendiendo a la conceptualización del Sistema de Tutela Jurisdiccional realizada por el profesor Sumaria, se puede señalar que el Sistema de Tutela Jurisdiccional viene a ser el conjunto de reglas, principios, elementos y procedimientos que interactúan racionalmente a fin de tutelar y garantizar el respeto de los derechos tutelados materialmente, permitiendo a la sociedad — partes — que mediante el ejercicio del derecho de acción puedan acceder a la jurisdicción a cargo del Estado - juez-, en busca de obtener justicia.

Atendiendo a que los sistemas jurídicos (contemporáneos) permiten organizar jurídicamente a un Estado, se puede advertir que existen variantes en el sistema de tutela jurisdiccional, por ejemplo, el Sistema del Common Law prevé un sistema de tutela jurisdiccional individual y un sistema de tutela jurisdiccional colectivo. Ello nos permite advertir las variantes que presenta el sistema de tutela jurisdiccional.

\section{Cuadro N. ${ }^{\circ} 3$}

\begin{tabular}{|c|c|}
\hline \multicolumn{2}{|c|}{ Sistemas de Tutela Jurisdiccional Civil } \\
\hline $\begin{array}{c}\text { Sistema de Tutela } \\
\text { Jurisdiccional Individual }\end{array}$ & $\begin{array}{c}\text { Sistema de Tutela } \\
\text { Jurisdiccional Colectivo }\end{array}$ \\
\hline $\begin{array}{c}\text { Ejercicio del derecho de } \\
\text { acción } \\
\text { Individual }\end{array}$ & $\begin{array}{c}\text { Ejercicio del derecho de } \\
\text { acción colectivo }\end{array}$ \\
\hline $\begin{array}{c}\text { Acceso a tutela } \\
\text { jurisdiccional } \\
\text { Individual }\end{array}$ & $\begin{array}{c}\text { Acceso a tutela } \\
\text { jurisdiccional } \\
\text { colectiva }\end{array}$ \\
\hline Proceso individual & Proceso colectivo \\
\hline
\end{tabular}

Fuente: Mamani Olivera, 2019

En este extremo, corresponde señalar que las modalidades de tutela jurisdiccional (individual y colectiva) obedecen al tipo de tutela material de derecho, la que puede ser tutela de derechos individuales y tutela de derechos colectivos. En palabras de Lions Signoret (2016), los derechos son el resultado de un proceso evolutivo de reconocimiento y protección, en un primer momento fueron derechos individuales, que al ser intrínsecos al ser humano han permitido el desarrollo de su personalidad, permitiéndoles obtener libertades de accionar ante el poder público.

En esencia, el Sistema de Tutela Jurisdiccional comprende dos subsistemas: el Sistema de Tutela Jurisdiccional Individual y el Sistema de Tutela Jurisdiccional Colectivo. En el primero, corresponde referirnos al derecho accionar personal o individualmente y consiguientemente de la tutela jurisdiccio- 
nal de carácter individual, es decir, se presenta una interacción entre la acción individual y la tutela jurisdiccional individual en un proceso individual. Por su parte, en el caso de la Tutela Jurisdiccional Colectiva, la interacción se presenta entre el derecho de accionar colectiva y la tutela jurisdiccional colectiva, a través de un proceso colectivo.

En relación a la tutela jurisdiccional individual, desde un enfoque legislativo, esta institución se remonta al Código de Procedimientos Civil Francés de 1806, cuya influencia ha trascendido al continente europeo, siendo el referente principal y de influencia mundial, sobre todo para la familia jurídica Romano Germánica o del Civil Law, y que ha sido adoptada por nuestra legislación, así se puede advertir en nuestro vigente Código Procesal Civil, cuando el artículo IV del título preliminar señala:

El proceso se promueve solo a iniciativa de parte, la que invocará interés y legitimidad para obrar, no requieren invocarlos el Ministerio Público, el procurador oficioso ni quien defiende intereses difusos.

Por su parte, el artículo 2 del mismo cuerpo normativo prescribe:

Por el derecho de acción todo sujeto, en ejercicio de su derecho a la tutela jurisdiccional efectiva y en forma directa o a través de representante legal o apoderado, puede recurrir al órgano jurisdiccional pidiendo la solución a un conflicto de intereses intersubjetivo o a una incertidumbre jurídica.

En similar sentido, se prescribe en el artículo IV del Código Civil: «Para ejercitar o contestar una acción es necesario tener legítimo interés económico o moral [...].»

\section{SISTEMA DE TUTELA JURISDICCIONAL COLECTIVO}

Según refiere Albino Zavascki (2005), «No se debe confundir la defensa de derechos colectivos con la defensa colectiva de derechos» (p. 26). Puesto que al referirnos al Sistema de Tutela Jurisdiccional no referimos a la tutela colectiva de derechos, y comprende la defensa de derechos difusos, colectivos propiamente dichos y los individuales homogéneos.

\subsection{Reseña Histórica}

El Sistema de Tutela Jurisdiccional Colectivo encuentra su antecedente principal en una institución jurídica propia del Common Law, la denominada «Class Actions». Su estudio, a partir de la revisión realizada por Mauro Cappelletti, ha permitido su entendimiento y difusión en parte de Europa y Sudamérica, en esta última, resulta importante la labor realizada por el profesor brasileño Antonio Gidi.

Según refieren los profesores Didier Jr., Fredie; Zaneti Jr. y Hermes (2014):

Las primeras acciones colectivas se remontan a Inglaterra siglo xii cuando un párroco de nombre Martín presentó una acción contra los pobladores de Nuthamstead a fin de que se le entregue ofrendas y servicios diarios. (p. 25)

\subsubsection{En el Common Law}

Las Class Actions representan una institución importante que encontró acogida en el Derecho norteamericano, representando un proceso distinto al ordinario, que permite la resolución de conflictos y que sus efectos puedan ser extendidos a otras personas que pertenezcan al mismo grupo a clase afectada.

Como modelo procesal permite otorgar una tutela jurisdiccional colectiva, que a fin de proteger a los miembros de un grupo o clases, se dé apertura legitimatoria, puesto que debido a factores o causas relacionadas con falta de interés de personas, desconocimiento de derechos, desconocimiento de la existencia de tutela, costos judiciales y entre otros, encuentran una tutela costosa y complicada.

Las Class Actions han sido reguladas en 1938 mediante la regla $\mathrm{N} .{ }^{\circ} 23$ (Federal Rules), modificadas en 1966 y, posteriormente, en el año 2005, como una estrategia del Congreso norteamericano para traspasar a la jurisdicción federal cierto tipo de casos (Carnota, 2012, pp. 96-97). La regla 23 no crea especies o categorías abstractas de intereses o derechos; lo que hace es establecer algunos requisitos para las acciones colectivas, así: 
Cuadro: N. ${ }^{\circ} 4$

\section{Class Actions - Regla 23}

Regla 23.a. Prerequisites. One or more members of a class may sue or be sued as representative parties on behalf of all members only if:

(1) The class is so numerous that joinder of all members is impracticable;

(2) There are questions of law or fact common to the class;

(3) The claims or defenses of the representative parties are typical of the claims or defenses of the class. y

(4) The representative parties will fairly and adequately protect the interests of the class.
Regla 23.a. Requisitos previos. Uno o más miembros de una clase pueden demandar o ser demandado, a las partes representativas en nombre de todos los miembros solamente si:

(1) La clase es tan numeroso, que la acumulación de todos los miembros es impracticable;

(2) Hay cuestiones de hecho o de derecho común a la clase.

(3) Las reclamaciones o defensas de las partes representativas son típicas de las reclamaciones o defensas de la clase.

(4) Las partes representativas darán justa y adecuada protección de los intereses de la clase.

Fuente: Mamani Olivera, 2019

Según Barusso (2013):

Las Federal Rule of Civil Procedura N. ${ }^{\circ} 23$ establece los siguientes requisitos: 1) La noción de representación adecuada, que establece requisitos para que quien pretenda erigirse como representante del grupo o clase. 2) Debe estar dirigida a los integrantes de clase que estén ausentes, a fin de que la notificación sea practicable de forma adecuada y según las circunstancias. 3) El derecho a OpOut, es decir, la forma de poder ser excluido del proceso colectivo.

Esta regla, además, permite que el juez pueda asumir decisiones como Calificar si una acción es o no colectiva; -Especificar la parte de grupo que se encuentra representada; - Especificar la manera en que los intervinientes deban se comunicados.

Según refiere Hernández (1997), la importancia de la Class Action aparece cuando un perjuicio es causado a un grupo, y un miembro del mismo quiera demandar la reparación ante los tribunales, no solo por el perjuicio sufrido de forma individual, sino también por el sufrido por todos los miembros del grupo.

Según el profesor Taruffo, citado por Didier Jr., Fredie; Zaneti Jr., Hermes (2014, p. 57), la distinción con que cuenta las Class Actions es que lo que sentencia en este proceso tiene efectos vinculantes para todos los miembros del grupo o clase.

\subsubsection{En el sistema jurídico Romano Ger- mánico o Civil Law}

En la década de los años 70, profesores como Cappelletti y Garth (1988) presentaron un trabajo intitulado Acceso a la Justicia en la ciudad de Florencia, la peculiaridad de este trabajo permitió advertir en el tercer volumen una tipología de formas de acceder a la justicia; la forma en cómo se pasó de una justicia individualista a una justicia colectiva -Guido Clabrese; y una tercera referida de enfoque económico referido a la eficacia de productividad de instituciones judiciales.

El análisis realizado por Cappelletti permitió advertir que, entre los intereses públicos y los intereses privados, existen otro tipo de intereses que no alcanzan a ser públicos ni privados, Cappelletti, se refería a los intereses de grupos, de personas o clases de personas, también denominadas categorías de personas; a esta categoría de intereses intermedios les denomina intereses transindividuales o supraindividuales. Adviértase el aporte realizado por este autor, quien tuvo como finalidad evidenciar la existencia de intereses intermedios, los cuales requieren de un tipo de tutela diferenciada denominada tutela colectiva.

El trabajo de Cappelletti encuentra un importante escenario legislativo en Europa, donde algunos países implementan algunas variantes de este tipo de tutela colectiva, como se puede apreciar en el siguiente cuadro. 
Cuadro: $\mathbf{N}^{\circ} 5$

\begin{tabular}{|l|l|l|}
\hline \multicolumn{2}{|c|}{ Modelos de tutela colectiva de derechos } \\
\hline País & Implementa & \multicolumn{1}{c|}{ (Apertura legitimatoria) Tiene legitimación a: } \\
\hline Inglaterra & $\begin{array}{l}\text { Relator } \\
\text { Actions }\end{array}$ & $\begin{array}{l}\text { El Attoney General, también llamado en otros sistemas el Fiscal del Estado, el } \\
\text { Procurador General de Justicia, el Ministerio Público. }\end{array}$ \\
\hline Alemania & $\begin{array}{l}\text { Acciones } \\
\text { Asociativas }\end{array}$ & $\begin{array}{l}\text { Se construye una forma le legitimación ordinaria, este modelo tiene la etiqueta } \\
\text { alemana sobre normas generales de contratación, da una Ley para el reglamento de } \\
\text { las clausulas generales de los negocios, también denominada acciones asociativas. }\end{array}$ \\
\hline Francia & $\begin{array}{l}\text { Associations } \\
\text { Declarées }\end{array}$ & $\begin{array}{l}\text { Con la Ley Royer N. }{ }^{\circ} \text { 1193 de 1973, con la que Francia podrá tener una class } \\
\text { action for damages op-in (litigios agregados), consagra la acción pública a las } \\
\text { asociaciones }\end{array}$ \\
\hline Italia & $\begin{array}{l}\text { Acción } \\
\text { Colectiva }\end{array}$ & $\begin{array}{l}\text { En 1970, en el estatuto de trabajo, que preveía una especial legitimación para los } \\
\text { sindicatos. }\end{array}$ \\
\hline España & $\begin{array}{l}\text { Acción Civil } \\
\text { Pública }\end{array}$ & $\begin{array}{l}\text { Constitución Española de 1978 consagra el derecho de los ciudadanos a participar } \\
\text { en los asuntos públicos, directamente o por medio de sus representantes, para la } \\
\text { cual establece el derecho de petición individual y colectiva en el artículo 29. }\end{array}$ \\
\hline
\end{tabular}

Fuente: Mamani Olivera, 2019

A nivel sudamericano, es importante la presencia que ha tenido la doctrina brasileña, como la laborar realizada en un primer comento por Ada Pellegrini, Kazuo Watanabe, Antonio Gidi, quienes con sus trabajos contribuyeron junto a diferentes autores de diferentes países iberoamericanos a la redacción del Código Modelo de Proceso Colectivos para Iberoamérica.

Avance doctrinario que ha permitido que a nivel legislativo Brasil cuente con legislación importante relacionada a la tutela de intereses difusos y colectivos, entre la que se puede mencionar a la Ley de Acción Popular de 1977, Acción Civil Pública de 1985, la promulgación del Código de Defensa del Consumidor de 1990.

\subsubsection{Derecho protegido}

En el sistema de Tutela Jurisdiccional Individual:

\section{Cuadro N. ${ }^{\circ} 6$}

\begin{tabular}{|c|c|c|c|}
\hline \multicolumn{2}{|c|}{$\begin{array}{c}\text { Sistema de Tutela Jurisdiccional Individual } \\
\text { (tutela derechos individuales) }\end{array}$} \\
\hline Tipo & \multicolumn{3}{|c|}{ Comprende } \\
\hline Individual & $\begin{array}{c}\text { Ejercicio } \\
\text { individual } \\
\text { del derecho } \\
\text { de acción }\end{array}$ & $\begin{array}{c}\text { Acceso } \\
\text { individual a } \\
\text { jurisdicción }\end{array}$ & $\begin{array}{c}\text { Participación } \\
\text { individual en el } \\
\text { proceso }\end{array}$ \\
\hline
\end{tabular}

Fuente: Mamani Olivera, 2019
En el Sistema de Tutela Jurisdiccional Colectivo se tiene:

A nivel Doctrinario

\section{Cuadro $N^{\circ} 7$}

Tipología de los Derechos Supraindividuales o de Incidencia Colectiva

\section{Código Modelo de Procesos Colectivos} para Iberoamérica

(aprobado en caracas el 28-10-2004)

Art ${ }^{\circ}$. Ámbito de aplicación de la acción colectiva. La acción colectiva será ejercida para hacer valer pretensiones de tutela de:

I. Intereses o derechos difusos, así entendidos los supraindividuales, de naturaleza indivisible, de que sea titular un grupo, categoría o clase de personas ligadas por circunstancias de hecho o vinculadas entre sí o con la parte contraria por una relación jurídica base;

II. Intereses o derechos individuales homogéneos, así entendido el conjunto de derechos subjetivos individuales, provenientes de origen común, de que sean titulares los miembros de un grupo, categoría o clase.

Fuente: Mamani Olivera, 2019 
A nivel Jurisprudencial

\section{Cuadro N. ${ }^{\circ} 8$}

Tipología de los Derechos Supraindividuales o de Incidencia Colectiva

\begin{tabular}{|l|l|l|}
\hline \multicolumn{3}{|l|}{ Caso Halabi - Argentina } \\
\hline \multirow{4}{*}{ Derechos } & Individuales \\
\cline { 2 - 3 } & $\begin{array}{l}\text { De Incidencia } \\
\text { Colectiva }\end{array}$ & Difusos \\
\cline { 3 - 3 } & Individuales Homogéneos \\
\hline
\end{tabular}

Fuente: Mamani Olivera, 2019

A nivel de legislación

Cuadro: $\mathbf{N}^{\circ} 9$

\begin{tabular}{|c|l|}
\hline \multicolumn{2}{|c|}{ Tipología de los Derechos Supraindividuales } \\
o de Incidencia Colectiva
\end{tabular}

Fuente: Mamani Olivera, 2019
A manera de resumen, diremos que la orientación a la tutela de derechos supraindividuales ha sido marcada a partir del Código Modelo de Procesos Colectivos para Iberoamérica, en el cual se contempla una tipología de derechos que comprende a los derechos difusos, colectivos e individuales homogéneos. Asimismo, el Código Civil y Comercial Argentino del año 2014, que a nivel legislativo regula los derechos de incidencia colectiva, siendo el primer código de Derecho Privado que tutela estos derechos (de incidencia colectiva) de manera expresa.

Según el profesor

\section{Cuadro: N..$^{\circ} 10$}

\section{Diferencias entre los Derechos Supraindividuales o de Incidencia Colectiva}

\begin{tabular}{|l|l|l|l|}
\hline $\begin{array}{c}\text { Intereses o } \\
\text { Derechos }\end{array}$ & \multicolumn{1}{|c|}{ Grupo } & Objeto & Origen \\
\hline Difusos & Indeterminable & Indivisible & $\begin{array}{l}\text { Situación } \\
\text { de hecho }\end{array}$ \\
\hline Colectivos & Determinable & Indivisible & $\begin{array}{l}\text { Relación } \\
\text { Jurídica }\end{array}$ \\
\hline $\begin{array}{l}\text { Individuales } \\
\text { Homogéneos }\end{array}$ & Determinable & Divisible & $\begin{array}{l}\text { Origen } \\
\text { común }\end{array}$ \\
\hline
\end{tabular}

Fuente: Mamani Olivera, 2019

\subsubsection{Acceso}

Al referirnos al acceso a tutela jurisdiccional colectiva, hemos de referirnos a la acción colectiva, y junto a ella a la representación adecuada.

En relación a la acción colectiva, hemos de citar a Didier Jr., Fredie; Zaneti Jr., Hermes, (2014), quienes referencian a que ella surge de la relación existente entre la materia litigiosa y la colectividad que requiere de tutela, es decir, corresponde poner atención a la materia litigiosa en discusión por sobre la estructura del proceso; siendo este aspecto el que justifica la presencia de la representación adecuada como una autorización para que cualquier interesado del grupo represente a distintos sujetos, quienes pueden ser identificables o no.

Asimismo, Gidi (2004) afirma: «La acción colectiva es una acción promovida por un represen- 
tante (legitimación colectiva), para proteger el derecho que pertenece a un grupo de personas (objeto de litigio) y cuya sentencia obligará al grupo como un todo (cosa juzgada)» (p. 31). Como se puede observar, en esta conceptualización realizada por el profesor Gidi, se puede advertir los elementos de la acción colectiva, como son los siguientes:

- La presencia de un representante, que tiene la denominación de representación adecuada. (Sujeto)

- La protección de derecho de un grupo o categoría de personas. (Causa)

- Los efectos de la cosa juzgada, con efectos expansivos. (Objeto)

Quien asume la representación adecuada es quien se encarga de materializar el ejercicio del derecho de acción colectiva, en palabras del profesor Gidi, la regulación que se realiza de la legitimación tiene como finalidad que los interesados -afectados- puedan tener sus intereses debidamente representados durante el juicio o proceso. Ello debido a que lo resuelto en la sentencia vinculara incluso a las partes que no formaron parte del proceso.

Es preciso diferenciar la representación adecuada del ejercicio conjunto del derecho de acción, para ello hemos de recurrir a lo expresado por Moreira José y Carlos Barbosa citados por Didier Jr., Fredie; Zaneti Jr., Hermes (2014) «El ejercicio conjunto de la acción no configura una acción colectiva. El cúmulo de diversos sujetos en una de las partes de la relación procesal apenas daría lugar a un litisconsorcio [...]» (pp. 34-35). Como se puede advertir, existe una diferencia sustancial entre la acción colectiva, propia de la tutela jurisdiccional colectiva y el ejercicio colectivo del derecho de acción o también denominado litisconsorcio, propio de la tutela jurisdiccional individual.

En relación a la cosa juzgada con efectos expansivos, el sistema de tutela jurisdiccional colectivo nos permite su aplicación en atención al tipo de derecho que se protege, así, si se protegen derechos difusos o colectivos, la cosa juzgada a aplicarse es la cosa juzgada Secundum Eventum Litis, es decir, que cuando la pretensión es fundada, los efectos de la sentencia son erga omnes; y en los casos en los que se protegen los derechos indivi- duales homogéneos se aplican la cosa juzgada Opt Out, es decir, la cosa juzgada se ha de extender a todos los integrantes de la colectividad, con excepción de aquellos que de forma voluntaria optaron por no ser parte del proceso colectivo.

Como se puede advertir, el Sistema de Tutela Jurisdiccional Colectivo permite el acceso a tutela jurisdiccional mediante el ejercicio del derecho de acción colectiva, el mismo que se encuentra íntimamente asociado a la representación adecuada a fin de obtener la cosa juzgada con efectos expansivos.

\subsubsection{Legislación Sudamericana que se orienta hacia una Tutela Jurisdiccional Colectiva}

Entre los países que cuentan con legislación orientada a la tutela jurisdiccional civil colectiva, se encuentran Argentina, Colombia y México; el caso de Brasil es particular, debido a que su intento de brindar tutela colectiva en materia civil fue observado por el ejecutivo de dicho país.

\section{Brasil}

Uno de los últimos aportes, por parte de la legislación brasileña en relación a la tutela jurisdiccional civil colectiva, lo encontramos en el artículo 333 del Código de Procesos Civiles de 2015, el cual prescribía:

Atendiendo a los presupuestos de relevancia social y de dificultad de formación de litisconsorcio, el juez a requerimiento del Ministerio Público o de la Defensoría Pública, escuchando al autor, podrá convertir en colectiva la acción individual que vincule el pedido que:

I. Tenga alcance colectivo, en razón de la tutela del bien jurídico difuso o colectivo, así entendidos aquellos definidos por el artículo 81, párrafo único, inciso I y II, de la Ley N..$^{\circ} 8078$, de 1990 (Código del Consumidor) y cuya ofensa afecte en un mismo tiempo, a las esferas jurídicas del individuo o colectividad.

II. Tenga por objeto la solución de conflictos de intereses relativos a una misma relación jurídica plurilateral, cuya solución, por su naturaleza o por disposición de la ley, deba ser necesariamente uniforme, 
asegurando su tratamiento isonómico para todos los miembros del grupo [...].

Lo regulado en el artículo 333 del Código de Procesos Civil de 2015 hubiera constituido el mayor avance legislativo sobre tutela jurisdiccional civil colectiva, de no haber sido vetado por Dima Rousseff del ejecutivo. Ello no resta importancia al avance doctrinario realizado en Brasil, entre los que se puede citar a importantes procesalistas como Ada Pellegrini, Kazuo Watanabe y Antonio Gidi.

\section{Argentina}

El caso de la legislación argentina representa un hito importante en el escenario del Derecho Privado, puesto que el Código Civil y Comercial de 2014 en su artículo 14 prescribe: «En este código se reconocen: a) Los derechos individuales. b) Los derechos de incidencia colectiva. La ley no ampara el ejercicio abusivo de los derechos individuales cuando pueda afectar al ambiente y a los derechos de incidencia colectiva en general». Esta clasificación ha obedecido a la presencia del activismo judicial argentino, a partir del caso Halabi.

\section{Colombia}

La ley $N^{\circ} 472$ es, quizá, una de las legislaciones más importantes con que cuenta este país, que encuentra respaldo constitucional en el artículo 88 de la Constitución de 1993: «La ley regula las acciones populares para la protección de los derechos e intereses colectivos, relacionados con el patrimonio, el espacio, la seguridad y la salubridad pública, la moral administrativa, el ambiente, la libre competencia económica y otros de similar naturaleza que se definen en ella».

Por su parte, el artículo 1 de la ley N. 472 prescribe:

La presente Ley tiene por objeto regular las acciones populares y las acciones de grupo, de las que trata el artículo 88 de la Constitución política de Colombia. Estas acciones están orientadas a garantizar la defensa y protección de los derechos e intereses colectivos, así como los de grupo o de un número plural de personas.
El artículo 3 prescribe:

Acciones de grupo. Son aquellas acciones interpuestas por un número plural o conjunto de personas que reúnen condiciones uniformes respecto de una misma causa que originó perjuicios individuales para dichas personas. Las condiciones uniformes deben tener también lugar respecto de todos los elementos que configuran la responsabilidad. Las acciones de grupo se ejercen, exclusivamente, para obtener el reconocimiento y pago de indemnización de los perjuicios.

La legislación colombiana antes citada encuentra en el Código General de Procesos (2012) un complemento importante, así, se advierte de lo regulado en el artículo 2:

Toda persona o grupo de personas tiene derecho a la tutela jurisdiccional efectiva para el ejercicio de sus derechos y la defensa de sus intereses, con sujeción a un debido proceso de duración razonable. Los términos procesales se observan con diligencia y su incumplimiento injustificado será sancionado.

Como se puede advertir del contenido del presente artículo, el derecho de acceder a tutela jurisdiccional efectiva no solo se garantiza a la persona individual, sino también a un grupo de personas que busca la defensa de sus intereses.

\section{Estados Unidos Mexicanos}

A nivel constitucional, representa uno de los más importantes avances de tutela colectiva, así se puede apreciar del contenido de lo regulado en los artículos 2 y 17 de la Constitución Política de los Estados Unidos Mexicanos (Vigente desde 27 de agosto de 2018).

Artículo 2. [...] A. Esta Constitución reconoce y garantiza el derecho de los pueblos y las comunidades indígenas a la libre determinación y, a la autonomía para: [...] VIII. Acceder plenamente a la jurisdicción del Estado. Para garantizar ese derecho, en todos los juicios y procedimientos en que sean parte, individual o colectivamente, se deberán tener en cuenta sus costumbres y especialidades culturales 
respetando los preceptos de esta Constitución. Los indígenas tienen en todo tiempo el derecho a ser asistidos por intérpretes y defensores que tengan conocimiento de su lengua y cultura [...].

Artículo 17. [...] El Congreso de la Unión expedirá las leyes que regulen las acciones colectivas. Tales leyes determinarán las materias de aplicación, los procedimientos judiciales y los mecanismos de reparación del daño. Los jueces federales conocerán de forma exclusiva sobre estos procedimientos y mecanismos.

\section{CONCLUSIONES}

Un Sistema de Tutela Jurisdiccional se encuentra conformado por un conjunto de elementos, reglas, principios y procedimientos que se relacionan de forma racional entre sí, orientados a la protección y respeto de derechos.

- El Sistema de Tutela Jurisdiccional comprende dos subsistemas: 1) El Sistema de Tutela Jurisdiccional Individual, inspirado aún en el Código de Procedimientos Civiles Francés de 1806, adoptados por países como el nuestro (Artículo IV y 2 del Código Procesal Civil de 1984 concordado con el artículo VI del Código Civil de 1993). 2) El Sistema de Tutela Jurisdiccional Colectivo, propio de la familia jurídica del Common Law en la que se encuentra las Class Actions, la misma que en el Sistema Jurídico Romano Germánico ha adquirido la denominación de Acción Civil.

- Existe un importante desarrollo doctrinario y legislativo de la tutela jurisdiccional colectivo en el escenario civil, «Tutela Jurisdiccional Civil Colectiva», como se aprecia de la legislación colombiana, argentina y mexicana.

- Es importante tomar en cuenta el desarrollo de la Tutela Jurisdiccional Civil Colectiva, en nuestra legislación civil y procesal civil peruana y en su momento a nivel constitucional, teniendo en cuenta el desarrollo legislativo comparado que esta institución viene adquiriendo y sobre todo porque nuestra legislación civil debe adaptarse a los cambios sociales y económicos en los que los conflictos de naturaleza colectiva se hacen cada vez más frecuentes.

\section{Índice de Cuadros}

Cuadro N. ${ }^{\circ}$. Sistema de Tutela Jurisdiccional

Cuadro N. ${ }^{\circ}$ 2. Sistema de Tutela Jurisdiccional y su correlación con el criterio económico de eficiencia productiva

Cuadro N. ${ }^{\circ}$ 3. Sistemas de Tutela Jurisdiccional Civil Cuadro N. ${ }^{\circ}$ 4. Las Class Actions - Regla 23

Cuadro: $\mathrm{N}^{\circ}{ }^{5}$. Modelos de tutela colectiva de derechos Cuadro N. ${ }^{\circ}$ 6. Sistema de Tutela Jurisdiccional Individual (tutela derechos individuales)

Cuadro N. ${ }^{\circ}$. Tipología de los Derechos Supraindividuales o de Incidencia Colectiva

Cuadro N. ${ }^{\circ}$. Tipología de los Derechos Supraindividuales o de Incidencia Colectiva

Cuadro N. ${ }^{\circ}$ 9. Tipología de los Derechos Supraindividuales o de Incidencia Colectiva

Cuadro: N. ${ }^{\circ}$ 10. Diferencias entre los Derechos Supraindividuales o de Incidencia Colectiva

\section{BIBLIOGRAFÍA}

Albino Zavascki, T. (2005). Proceso colectivo: Tutela de Derecho Colectivos y Tutela Colectiva de Derechos. Porto Alegre: Universidad Federal de Rio Grande Del Sur. Recuperado de: https://www.lume.ufrgs.br/bitstream/handle/10183/4574/000502398.pdf

Alexy, R. (J. Seña, trad.). (2004). El Concepto y la Validez del Derecho. 2. ${ }^{\text {a }}$ ed. Barcelona: Gedisa.

Apolín Meza, D. L. (2012). La Protección de los Derechos Individuales Homogéneos y los Problemas de Acceso a la Jurisdicción a través del Proceso Civil. Derecho \& Sociedad, pp. 185-214.

Ariano Deho, E. (2003). El Problema del Proceso Civil. Lima: Jurista Editores.

Barusso, L. (2013). Acciones Colectivas en la Ley de Defensa del Consumidor de Argentina. Derecho \& Sociedad, pp. 205-214.

Cappelletti, Mauro; Garth, Bryant (S. Fabris, Ed., \& E. Gracie Northfleet, trad.). (1988). Acceso á Justica. Porto Alegre: Biblioteca tribunal do Justica do RS.

Carnota, W. F. (2012). Las Acciones de Clase desde los Estados Unidos a la Argentina. Anuario Iberoamericano de Justicia Constitucional, pp. 
93-106. Recuperado de: https://dialnet.unirioja.es/descarga/articulo/4081430.pdf

Código Civil. (8 de junio de 2019). Recuperado de: spijlibre.minjus.gob.pe y http://spijlibre.minjus. gob.pe/normativa_libre/main.asp

Código Civil Comercial. (2015). Recuperado de: http://www.saij.gob.ar/docs-f/codigo/Codigo_ Civil_y_Comercial_de_la_Nacion.pdf

Código Civil y Comercial Argentino. (25 de junio de 2019). Recuperado de: http://www.saij.gob.ar/ docs-f/codigo/Codigo_Civil_y_Comercial_de_ la_Nacion.pdf

Código Civil y Procesal Civil. (10 de junio de 2019). Recuperado de: http://spijlibre.minjus.gob.pe/ normativa_libre/main.asp

Código de Procedimientos Civiles. (25 de Mayo de 2019). Recuperado de: http://www.planalto. gov.br. Obtenido de http://www.planalto.gov. br: y http://www.planalto.gov.br/ccivil_03/_ ato2015-2018/2015/lei/l13105.htm

David, R., \& Jauffret Spinosi, C. (2010). Los Grandes Sistemas Jurídicos Contemporáneos. México: UNAM.

Didier Jr., Fredie; Zaneti Jr., Hermes. (2014). Curso de Direito Processual Civil. Salvador - Bahia, Brasil: Jus PODIUM.

Gidi, A. (L. Cabrera Acevedo, trad.). (2004). Las Acciones Colectivas y a Tutela de los Derechos Difusos, Colectivos Individuales en Brasil: Un modelo para paises de derecho civil. México: Instituto de Investigaciones Juridicas UNAM.

Hernández Martínez, M. (1997). Mecanismos de Tutela de los Intereses Difusos y Colectivos. México: UNAM.
Huerta Ochoa, C. (2003). Conflictor Normativos. México: Instituto de Investigaciones Jurídicas de la UNAM.

Lions Signoret, M. (2016). Los derechos individuales en la historia y en la doctrina. Boletín del Instituto de Derecho Comparado de México. pp. 33-60.

Mamani Olivera, V. (2019). Sistemas de Tutela Jurisdiccional Civil y Regulación de Derechos Individuales Homogéneos en el Perú (Tesis). Cusco.

Raz , J. (R. Tamayo y Salmorán, ed.). (1986). El Concepto de Sistema Jurídico. México: UNAM.

Real Académia Española. (30 de noviembre de 2018). Recuperado de: https://dle.rae.es/?id= NpxaH7S

Rodríguez, J. L. (2015). Sistema Jurídico. En J. L. Fabra Zamora, V. Rodríguez Blanco, \& J. L. Fabra Zamora (ed.). Enciclopedia de Filosofía y Teoría del Derecho. Vol. 2. pp. 979-1018. México: Instituto de Investigaciones Jurídicas UNAM. Recuperado de: https://archivos.juridicas.unam.mx/www/bjv/libros/8/3796/1.pdf

Sumaria Benavente, O. (2010). Sistemas Procesales: El Sistema de Tutela Jurisdiccional y la Relación con el Sistema Político. Themis 58, pp. 11-22.

Tamayo y Salmorán, R. (1976). Sobre el Sistema Jurídico y su Creación. Mexico: UNAM.

Vervic, F. (25 de junio de 2019). Recuperado de: http://escuela.asesoria.gba.gov.ar/documentos/121/VERBIC,\%202012-05_Tutela_Colectiva_de_Derechos_en_Argentina_(RDP_numero_especial_Conferencia_IAPL-IIDP).pdf 